\title{
Novel strategies in the treatment of castration-resistant prostate cancer (Review)
}

\author{
ILARIA MARECH $^{1}$, ANGELO VACCA ${ }^{1}$, GIROLAMO RANIERI $^{2}$, \\ ANTONIO GNONI $^{3}$ and FRANCO DAMMACCO ${ }^{1}$ \\ ${ }^{1}$ Department of Internal Medicine and Clinical Oncology, University of Bari Medical School; \\ ${ }^{2}$ Interventional Radiology Unit with Integrated Section of Medical Oncology, National Cancer Institute \\ Giovanni Paolo II, Bari; ${ }^{3}$ Medical Oncology Unit, Hospital Vito Fazzi, Lecce, Italy
}

Received November 10, 2011; Accepted December 29, 2011

DOI: 10.3892/ijo.2012.1364

\begin{abstract}
Prostate cancer is the most common cancer in men in Europe and the United States, and the third leading cause of death from cancer in Europe. Survival of prostate cancer cells is dependent on the activation of androgen receptors (AR), that are overexpressed in this tumor. Furthermore, $\sim 90 \%$ of prostate cancer patients that respond to first-line androgen deprivation therapy (ADT) undergo rapid progression. This condition is defined as castration-resistant prostate cancer (CRPC). Docetaxelbased regimens significantly improve overall survival (OS) in patients with CRPC and represent the only treatment strategy approved by the Food and Drug Administration (FDA). Recently, abiraterone (second hormonal therapy) and cabazitaxel (new taxane) have been shown to improve survival in patients with CRPC who progressed following docetaxel-based chemotherapy. Vaccine therapy has also been demonstrated to improve OS in patients with asymptomatic or minimally symptomatic metastatic CRPC. Additional therapeutic targets have been analyzed in prostate cancer, including apoptosis, angiogenic receptors, vitamin D and Src pathways. Several phase II studies are ongoing. The high frequency of prostate cancer-related metastatic bone disease has led to consider this pathway as a therapeutic target. To this end, several bone-targeted agents have been investigated, most notably zoledronic acid, which is highly effective at stabilizing the bone and preventing skeletal complications. More recently, a nuclear factor- $\beta$ ligand (RANKL) inhibitor, denosumab, has been developed for the treatment of bone metastases.
\end{abstract}

Correspondence to: Dr Girolamo Ranieri, Interventional Radiology Unit, with Integrated Section of Medical Oncology, National Cancer Institute Giovanni, Paolo II, 70124 Bari, Italy

E-mail: giroran@tiscalinet.it

Key words: angiogenesis, apoptosis, bone-targeted therapy, castrateresistant prostate cancer, docetaxel, vaccine therapy

\section{Contents}

1. Introduction

2. Systemic chemotherapy

3. Agents under development

4. Conclusions

\section{Introduction}

Cancer of the prostate is the leading type of cancer and the second cause of cancer-related deaths among men in Europe and the USA (1). Most patients have a low-risk, clinically localized disease at diagnosis and can be treated effectively with surgery and radiation $(2,3)$. However, $\sim 10-20 \%$ of patients are diagnosed with locally advanced or metastatic disease and an additional, sizable proportion will progress despite surgery and radiation $(3,4)$. Thus, advanced prostate cancer remains a significant treatment challenge.

The mainstay of treatment for metastatic prostate cancer is androgen deprivation therapy (ADT), such as luteinizing hormone-releasing hormone (LHRH) agonists, anti-androgen and their combination, named maximal androgen blockade (MAB) (5-7). Although the majority of patients with metastatic disease initially respond to hormonal therapy, almost all of them will eventually progress after an average 18-24 months, despite maintenance of castrate serum testosterone levels $<50 \mathrm{ng} / \mathrm{ml}$ (8). Castrationresistant prostate cancer (CRPC) presentation subtypes include biochemical progression prostate-specific antigen (PSA $>4 \mathrm{ng} / \mathrm{ml}$ ), clinical and/or symptomatic progression, or both (biochemical first). In patients with CRPC, treatment options are based on the addition of anti-androgens, if they had been previously treated with LHRH agonists; the addition of LHRH agonists, if they had been previously given anti-androgens; or anti-androgen withdrawal for those previously treated with MAB. Response to anti-androgen withdrawal was initially observed in patients who discontinued flutamide upon the development of CRPC (9). After secondary hormonal treatment, most patients will progress within several years (10), and effective treatment options for CRPC remain limited. 
In the late 1990s, chemotherapy with mitoxantrone-based regimens was shown to provide some palliative benefits in CRPC $(11,12)$, although no therapy has been shown to improve OS. The most dramatic shift in the treatment paradigm came in 2004, with the demonstration in the trials named TAX 327 and South Western Oncology Group (SWOG) 9916 that docetaxelbased chemotherapy provides a significant survival benefit in patients with CRPC $(4,13)$. This has led to a significant expansion of the role of chemotherapy in the management of prostate cancer, which is now being investigated in the management of locally advanced hormone-sensitive disease. Furthermore, novel targeted therapies targeting several pathways in prostate cancer cells are under investigation.

\section{Systemic chemotherapy}

It was considered for the treatment of prostate cancer only in mid-1990s. Mitoxantrone, in combination with prednisone, was shown to play a role in the treatment of patients with CRPC (12,14-16). A Canadian phase III study in patients with symptomatic CRPC demonstrated that, compared to prednisone alone, this combination resulted in a significant improvement in both response rate $(29 \%$ versus $12 \%$ : $\mathrm{p}=0.01)$ and duration of palliation (43 versus 18 weeks: $\mathrm{p}<0.0001)(12)$. In a phase III US Oncology study in patients with asymptomatic CRPC, mitoxantrone plus prednisone induced a significantly superior outcome in $\geq 50 \%$ PSA reduction ( $48 \%$ versus $24 \%$ : $\mathrm{p}=0.007$ ), albeit with no difference in median time to treatment failure, median time to progression, or median survival (17). Although unable to achieve an improvement in OS, mitoxantrone was approved by the US Food and Drug Administration (FDA) for the palliative treatment of CRPC in 1996 (14-16).

In 2004, two randomized clinical trials (TAX 327 and SWOG 9916) demonstrated for the first time a survival advantage with docetaxel-based chemotherapy compared to mitoxantrone in patients with metastatic CRPC $(4,13)$. In the TAX 327 study, patients with metastatic CRPC were randomized to one of the following treatment arms: i) thrice-weekly docetaxel; ii) docetaxel weekly for 5 out of every 6 weeks; iii) control therapy with thrice-weekly mitoxantrone. The study showed that the median survival of patients treated with thrice-weekly docetaxel was significantly longer than that of patients treated with mitoxantrone (18.9 vs. 16.5 months; $\mathrm{p}=0.009)$. Also, this schedule yielded significantly superior outcomes with respect to $\geq 50 \%$ PSA reduction (45 vs. $32 \%$ : $\mathrm{p}<0.001$ ), pain reduction ( 35 vs. $22 \%$ : $\mathrm{p}=0.01$ ), and improvement in quality of life (22 vs. 13\%: $\mathrm{p}=0.009$ ) compared to mitoxantrone (4). In the SWOG 9916 study, patients with metastatic CRPC were randomized to receive docetaxel plus estramustine or mitoxantrone plus prednisone. Docetaxel plus estramustine therapy resulted in significant improvement in median OS (17.5 vs. 15.6 months: $\mathrm{p}=0.02)$, median time to progression (TTP) (6.3 vs. 3.2 months: $\mathrm{p}<0.001$ ), and $\geq 50 \%$ PSA reduction (50\% vs. $27 \%$ : $\mathrm{p}<0.001)$ (13).

Based on these results, thrice-weekly docetaxel with prednisone therapy was approved by the FDA for the treatment of metastatic CRPC in May 2004 and is now widely accepted as the standard of care for chemotherapy in patients with CRPC (14-16). A recent update of the TAX 327 study, stemmed from an extended follow-up, is consistent with previously reported results. The median survival of patients treated with thrice- weekly docetaxel was significantly longer than that of patients treated with mitoxantrone (19.2 vs. 16.3 months: $p=0.004)$. More patients survived $\geq 3$ years in the thrice-weekly docetaxel arm than in the mitoxantrone arm (18.6 vs. 3.5\%) (18). This improved OS shown by the updated results was ascribed to an initial bias, due to the great crossover into the thrice-weekly docetaxel arm.

\section{Agents under development}

Agents under development in clinical, ongoing studies are summarized in Table I.

Hormonal therapy. Disease progression despite effective ADT is a significant event in the natural history of prostate cancer $(4,13,19)$. Currently available anti-androgen therapies, that are often used with LHRH agonists, include flutamide, bicalutimide, and nilutimide. These drugs exhibit only moderate binding affinity for the androgen receptors (AR) (20), and this is a limiting factor for their therapeutic efficacy. Since they do not blockade the adrenal androgen production, specific inhibitors of adrenal androgen synthesis have been developed.

Abiraterone acetate (CB7630) is a potent, orally bioavailable, small molecule inhibitor of cytochrome P17, which catalyses two key reactions (17- $\alpha$-hydroxylase and 17,20 xylase) involved in androgen biosynthesis (21), thereby dramatically reducing both adrenal and intra-tumoral androgen production. A phase I/II study of abiraterone (at dose of 1,000 mg/day) in 54 patients with CRPC showed a $67 \%$ reduction in serum PSA level and a $37.5 \%$ partial response. These results clearly support the hypothesis that CRPC remains sensitive to endocrine therapy in most patients, and show that abiraterone is a promising agent for the treatment of CRPC (22). Based on these results, a phase III trial (NCT00638690) in patients previously treated with 1 or 2 chemotherapy regimens, one of which contained docetaxel, has recently completed enrolment of 1,195 patients, comparing the efficacy and safety of abiraterone acetate plus prednisone versus placebo plus prednisone. Patients were allowed to receive treatment until documented disease progression (of all 3 types, namely: PSA progression, radiographic progression and symptomatic or clinical progression) or unacceptable toxicity. Primary efficacy endpoint is OS, whereas secondary endpoints are PSA response rate, time to PSA progression and radiographic progression-free survival (R-PFS) $(23,24)$. Ad interim analysis has shown an improvement in OS (14.8 vs. 10.9 months: $\mathrm{p}<0.0001, \mathrm{HR}=0.64)$, PSA response rate ( 38 vs. $10.1 \%$ : $\mathrm{p}<0.0001$ ), time to PSA progression (10.2 vs. 6.6 months: $\mathrm{p}<0.0001)$, R-PFS (5.6 vs. 3.6 months: $\mathrm{p}<0.0001)$. Adverse events, more frequent in the Abiraterone arm, were fluid retention (30.5 vs. $22.3 \%$ ), hypokalemia (17.1 vs. $8.4 \%$ ) and cardiac disorders (12.5 vs. 10.4\%). Grade 3 and 4 hypokalemia was observed in $3.8 \%$ of the Abiraterone group versus $0.8 \%$ of the placebo group. Grade 3 and 4 hypertension was observed in 1.3 vs. $0.3 \%$ of the placebo group (25).

Other chemotherapy agents. The demonstration that chemotherapy can, indeed, improve survival in this patient population and to an extent similar to that seen in other chemotherapysensitive tumor types has challenged the notion that CRPC is chemotherapy refractory and enhanced the efforts to develop more effective chemotherapy regimens and assess the possi- 
Table I. Selected agents under development for castration-resistant prostate cancer.

\begin{tabular}{lcc}
\hline Drug & Mechanism of action & Study \\
design & FDA \\
approval
\end{tabular}

Hormonal therapy

Abiraterone

Other chemotherapy agents

Cabazitaxel

Satraplatin

Vaccines

Sipileucel

GVAX

PROSTVAC-VF

Anti-apoptotic agents

Oblimersen

Angiogenesis inhibitors

Bevacizumab

Aflibercept

Tyrosine kinase inhibitors

Dasatinib

Sorafenib

Sunitinib

Vitamin D analogues

Calcitriol

Endothelin receptor antagonists

Atrasentan

Zibotentan
Inhibitor of cytochrome p17

Phase III

Yes (US FDA)

Microtubule inhibitor

Binds to the DNA's cancer cells

Phase III

Phase III

Yes (US FDA)

No

Elicit an immune response against

cancer cells carrying the PAP antigen

Activate dendritic cells expressing GM-CSF

Stimulate T-cell responses expressing PSA sequence

which alteration in HLA-A2 epitope

Phase III

Yes (US FDA)

Phase II

Phase III

No

bcl-2 antisense oligonucleotide

Phase II

Anti-VEGF inhibitor

Phase III

Phase III

No

Anti-VEGF inhibitor

Phase III

No

Inhibitor of Raf kinase, VEGFR-1, VEGFR-2,

VEGFR-3, PDGFR-B, c-Kit, FLT-3, RET

Inhibitor of VEGFR 1-3,

PDGFR $\alpha-\beta, \mathrm{c}-\mathrm{Kit}$, FLT3, RET

Phase II

Phase II

Phase III

No

Inhibits proliferation and stimulates apoptosis activating VDR-RXR complex

Anti-ETA and ETB receptors

Anti-ETA receptors
Phase III

Phase III
No

No

PDGFR, platelet-derived growth factor receptor; VDR, vitamin D receptor; RXR, retinoic acid X receptor.

bility of a second-line therapy. To overcome the emergence of taxane resistance $(26,27)$, a new semi-synthetic taxane, cabazitaxel (XRP6258), was tested in preclinical and clinical studies. It has been shown to exert similar efficacy compared with docetaxel against sensitive cell lines and tumor models, in that it was active against tumor cells/models resistant to currently available taxanes and was more potent than docetaxel against multidrug resistance transporter (MDR-1)-expressing tumor cells resistant to taxanes $(27,28)$.

In the randomized phase III treatment of hormonerefractory metastatic prostate cancer previously treated with a taxotere-containing regimen (TROPIC) study, 755 patients with metastatic CRPC, who progressed during or after docetaxel-based chemotherapy, were randomized to receive cabazitaxel $\left(25 \mathrm{mg} / \mathrm{m}^{2}\right.$ thrice-weekly) or mitoxantrone every 3 weeks, with the addition of oral prednisone daily. Cabazitaxel therapy resulted in improved median progression-free survival
(PFS) (2.8 vs. 1.4 months: $\mathrm{p}<0.0001)$, median OS (15.1 vs. 12.7 months: $\mathrm{p}<0.0001)$ compared to mitoxantrone. Cabazitaxel has demonstrated an improvement in tumor assessment (response rate 14.4 vs. $4.4 \%$ : $\mathrm{p}<0.0005, \mathrm{HR}=0.64)$, PSA reduction $(39.2$ vs. $17.8 \%$ : $\mathrm{p}<0.0002)$, pain control (9.2 vs. $7.8 \%$ : $\mathrm{p}<0.6286)$. The most common grade 3-4 toxicities were neutropenia, which was observed in $82 \%$ of patients in the cabazitaxel arm compared with $58 \%$ of patients in the mitoxantrone arm and diarrhea grade $3-4$ (6.2\% in cabazitaxel arm versus $0.3 \%$ in mitoxantrone arm) (29). Total deaths during the study were similar in America $(0.9 \%$ in cabazitaxel arm versus $0.8 \%$ in mitoxantrone arm: $\mathrm{p}<0.0001, \mathrm{HR}=0.72$ ), whereas it was superior in the cabazitaxel group in Europe ( 4.9 vs. $3.0 \%$ : p<0.0001, HR=0.72). A European revision (30) of the hazard ratio by country group analysis showed that in countries other than American and European countries the higher number of deaths was correlated to an inadequate management of grade 3-4 adverse events in 
respect of American Society of Clinical Oncology (ASCO) guidelines, such as delayed dose reduction of cabazitaxel. Overall, cabazitaxel determined a $28 \%$ reduction of death risk $(\mathrm{p}<0.0001, \mathrm{HR}=0.72)$. On this basis, it was approved for second-line use in this setting by the US FDA in June 2010.

Satraplatin (JM216) is an orally bioavailable thirdgeneration platinum compound $(31,32)$, that has shown activity against CRPC cell lines and taxane-resistant cell lines in vitro. It appears as a good candidate for use in CRPC after failure of docetaxel (33). Results from a prematurely terminated, randomized, phase III trial combining satraplatin with prednisone as first-line therapy for CRPC suggested that it has promising antitumor activity compared with prednisone alone (32), and this led to a randomized, placebo-controlled, phase III trial of this regimen as second-line therapy. The Satraplatin and Prednisone Against Refractory Cancer (SPARC) trial enrolled 950 patients unresponsive to prior chemotherapy $(51 \%$ had received prior docetaxel): patients were randomized to receive satraplatin $\left(80 \mathrm{mg} / \mathrm{m}^{2}\right.$ x 5 days, q5 weeks) plus prednisone or prednisone plus placebo (34). The primary endpoint was PFS, defined by radiological progression, symptomatic progression (i.e. increased pain or need for bone radiation), skeletal events, or death. This study showed a highly significant improvement in PFS $(\mathrm{p}<0.001, \mathrm{HR}=0.69)$ and pain progression $(\mathrm{p}<0.001$, $\mathrm{HR}=0.67$ ). In addition, patients in the satraplatin arm had a $25 \%$ PSA response rate, a $7 \%$ objective tumor response rate, and a $24 \%$ pain response rate, which were all significantly better than with prednisone alone (12, 1, and $14 \%$, respectively) (34). However, due to the evidence of no OS benefit, satraplatin was not approved by the FDA.

Immunotherapy. Several immunotherapeutic agents have been investigated for the treatment of prostate cancer. Sipuleucel-T is an autologous dendritic cell vaccine designed to stimulate an immune response against prostate cancer. Sipuleucel-T consists of autologous peripheral blood mononuclear cells, including antigen-presenting cells, cultured with a recombinant fusion protein (PA2024) composed of prostatic acid phosphatase linked to granulocyte-macrophage colony-stimulating factor (GM-CSF) (35-38). The first phase III trial of sipuleucel-T (D9901) in patients with asymptomatic metastatic CRPC did not meet the primary endpoint of TTP (11.7 for sipuleucel-T versus 10 weeks for placebo: $\mathrm{p}=0.052$ ), but demonstrated improvement in median OS (25.9 for sipuleucel-T versus 21.4 months for placebo: $\mathrm{p}=0.01$ ) (36). A subsequent phase III Immunotherapy for Prostate Adenocarcinoma Treatment (IMPACT) trial of sipuleucel-T in patients with asymptomatic or minimally symptomatic metastatic CRPC shared a similar design to the original trial, but designated OS as the primary endpoint. Treatment with sipuleucel-T resulted in a 4.1-month improvement in median OS ( 25.8 vs. 21.7 months), with a $22 \%$ relative reduction in the risk of death $(\mathrm{p}=0.03, \mathrm{HR}=0.78)$ compared to placebo (38). These data led to the approval of sipuleucel-T for the treatment of asymptomatic or minimally symptomatic metastatic CRPC by the US FDA in April 2010 (39,40).

Other vaccine therapies with GVAX (cellular vaccine composed of two allogeneic prostate cancer cell lines, namely LNCaP and PC-3) showed in phase I and II trials more deaths in the GVAX arm than in the control arm and were obviously prematurely closed.
PROSTVAC-VF, consisting of a recombinant vaccinia vector as a priming immunization with subsequent multiple booster vaccinations, was examined in a phase II trial and did not meet the primary endpoint of PFS, but achieved an 8.5 month improvement in median OS (25.1 for PROSTVAC-VF versus 16.6 months for controls), and a $44 \%$ reduction in the death rate $(\mathrm{p}=0.006, \mathrm{HR}=10.56)$ at 3 years post-study (41). A phase III trial of PROSTVAC-VF has been planned but not yet carried out $(41,42)$.

Targeted therapy. Given the recent success of chemotherapy for the treatment of CRPC, there is a strong rationale to incorporate targeted agents into established regimens in an effort to further improve clinical outcomes. Mostly, targeted agents are combined with chemotherapy, similar to the approach taken in other solid tumors, but the value of this approach has yet to be shown in CRPC, and several important questions remain unanswered.

Anti-apoptotic agents. $\mathrm{Bcl}-2$ overexpression, which is observed in a high percentage of patients with CRPC, prevents apoptosis and has a critical role in the transition from androgendependent to androgen-independent tumor growth (43). This protein contributes to resistance to docetaxel. For this reason, a phase II study investigated the activity of oblimersen sodium, a bcl-2 antisense oligonucleotide, administered before docetaxel to patients with CRPC. Chemotherapy-naïve patients with prostate-specific antigen (PSA) progression and testosterone $\leq 0.5 \mathrm{ng} / \mathrm{ml}$ received docetaxel $75 \mathrm{mg} / \mathrm{m}^{2}$ on day 1 or oblimersen $7 \mathrm{mg} / \mathrm{kg} / \mathrm{day}$ by continuous i.v. infusion on days 1-7 with docetaxel $75 \mathrm{mg} / \mathrm{m}^{2}$ on day 5 every 3 weeks for 12 cycles. PSA response was observed in $46 \%$ and $37 \%$ of 57 and 54 patients treated with docetaxel and docetaxel-oblimersen, respectively. Partial response according to RECIST criteria was achieved in 18 and $24 \%$, respectively. Oblimersen added to docetaxel was associated with an increase in the incidence of grade $\geq 3$ fatigue, mucositis, and thrombocytopenia. Major toxic events were reported in 22.8 and $40.7 \%$ of patients with docetaxel and docetaxel-oblimersen, respectively (44).

Angiogenesis inhibitors. Angiogenesis inhibitors appear to have potential usefulness in the treatment of prostate cancer, as they do in many other solid tumors, because angiogenesis and lymphangiogenesis play important roles in the process of tumor progression and metastasis (45). Microvessel density and plasma vascular endothelial growth factor (VEGF) levels are both independent prognostic factors in prostate cancer $(46,47)$ and, in addition to stimulating neovascularization of the tumor, there is evidence to suggest that tumor-derived VEGF may directly stimulate tumor growth via activation of VEGFRs expressed on tumor cells $(48,49)$. Several classes of anti-angiogenic agents are being investigated in prostate cancer (49).

Bevacizumab is a recombinant humanized monoclonal antibody with anti-angiogenic activity through blockade of VEGF $(50,51)$. The phase II, CALGB 90006 study, in chemotherapynaïve metastatic CRPC patients showed that the combination of docetaxel, estramustine, and bevacizumab is able to induce $>50 \%$ PSA reduction in $75 \%$ of patients, and a partial response in 59\% of patients, with a median OS of 24 months (52). In a phase II study in patients with docetaxel-refractory CRPC, bevacizumab plus docetaxel resulted in $\geq 50 \%$ PSA reduction in $55 \%$ of patients, and a partial response in $37.5 \%$ of patients, 
with a median OS of 9 months (53). In the phase III, CALGB 90401 study, chemotherapy-naïve metastatic CRPC patients were randomized to receive docetaxel plus prednisone in combination with either bevacizumab or placebo. The results were recently presented at the 2010 ASCO Annual Meeting but, disappointingly, the addition of bevacizumab to docetaxel plus prednisone did not improve median OS (22.6 for the experimental arm versus 21.5 months for the control arm: $\mathrm{p}=0.181, \mathrm{HR}=0.91)(54)$.

Aflibercept (VEGF Trap) is a recombinant fusion protein consisting of the human VEGF extracellular domain fused to the $\mathrm{Fc}$ domain of an IgG antibody. It has a higher affinity for VEGF than bevacizumab in vitro (55). Aflibercept has shown promising activity in combination with various chemotherapy regimens for the treatment of advanced solid tumors (primarily colorectal, breast, and ovarian cancer) and is currently being investigated in combination with standard docetaxel/prednisone for the first-line treatment of metastatic CRPC. This randomized, placebo-controlled, phase III trial (VENICE; NCT00519285) will enrol 1,200 patients, and OS is the primary endpoint (56).

Tyrosine kinase inhibitors. Small molecule tyrosine kinase inhibitors (TKIs) have also been studied in prostate cancer, including dasatinib, sorafenib, and sunitinib. Several trials are ongoing.

The most promising TKI is dasatinib, that targets Src pathways (49). Src is overexpressed in prostate cancer, and correlates with disease progression (57). Dasatinib inhibits proliferation, cell adhesion, migration and invasion of prostate cancer cells in vitro (58). A phase II study CA180085 investigating the activity of dasatinib in patients with metastatic CRPC has been started (59). The primary endpoint is the composite response/stable disease (SD) rate, achieved in 13 of 47 (28\%) patients with 95\% confidence interval above the minimum anticipated response rate of $10 \%$. The secondary endpoint (lack of progression by both Response Evaluation Criteria In Solid Tumors (RECIST) and bone scan analysis) was met by $43 \%$ and $19 \%$ of patients on week 12 and 24, respectively. Thus, dasatinib may have a future role for patients with prostate cancer as both anti-tumor and bone-targeted agent. A randomized ongoing double-blind phase III trial comparing docetaxel combined with dasatinib to docetaxel combined with placebo (READY Trial) is presently open in 1,380 patients with metastatic CRPC. Its purpose is to determine whether OS can be prolonged in patients who receive dasatinib in addition to the standard docetaxel plus prednisone regimen (60).

Vitamin D analogues. Vitamin D receptor is implicated in several pathways in prostate cancer cells, principally in the regulations of cell differentiation and proliferation. Phase I studies have demonstrated that the use of vitamin D analogues is able to induce inhibition of proliferation and stimulates apoptosis in prostate cancer cells (61). A single-institution phase II study of docetaxel plus calcitriol in patients with metastatic CRPC demonstrated $\geq 50 \%$ PSA reduction in $81 \%$ of patients, with a median time to progression and median survival of 11.4 and 19.5 months, respectively (62). In the randomized phase II Androgen Independent Prostate Cancer Study of Calcitriol Enhancing Taxotere (ASCENT), patients with metastatic CRPC were randomized to receive docetaxel plus calcitriol (DN-101) or docetaxel monotherapy. Docetaxel plus calcitriol therapy did not show statistically significant improvement in $\geq 50 \%$ PSA reduction compared to docetaxel monotherapy (63 vs. $52 \%$ : $\mathrm{p}=0.07$ ), but multivariate analysis demonstrated a lower risk of death $(\mathrm{p}=0.004, \mathrm{HR}=0.67)(63)$. These results led to the initiation of the phase III ASCENT-2 study comparing docetaxel plus high dose calcitriol to docetaxel monotherapy. However, this study was closed early because of an unexpectedly higher death rate in the docetaxel plus calcitriol arm (64).

Endothelin receptor antagonists. Atrasentan is a selective endothelin A (ETA) receptor antagonist with a 1,800-fold greater affinity for ETA than ETB (65). A phase III trial of atrasentan in patients with metastatic CRPC showed that atrasentan did not improve time to disease progression $(\mathrm{p}=0.136, \mathrm{HR}=0.89)$ or OS ( $\mathrm{p}=0.775, \mathrm{HR}=0.97)$ compared to placebo (66). The second phase III trial of atrasentan in patients with non-metastatic CRPC demonstrated lengthening of PSA doubling time $(\mathrm{p}=0.031)$, and slowing of bone alkaline phosphatase increment $(\mathrm{p}<0.001)$ compared to placebo, but did not meet the primary endpoint of time to disease progression improvement $(\mathrm{p}=0.288)$ (66). A phase III trial of docetaxel with or without atrasentan in patients with metastatic CRPC is ongoing $(35,67)$.

Zibotentan (ZD4054) is a specific ETA receptor antagonist with no detectable binding to the ETB receptor $(65,68,69)$. Recently, the final analysis of the phase II trial of zibotentan in patients with asymptomatic or mildly symptomatic metastatic CRPC was reported (68). Consistent with previous analyses (69), zibotentan therapy did not meet the primary endpoint of time to progression. Although the difference in OS between the zibotentan and placebo arms was found to be decreased compared to the previous analyses, zibotentan therapy resulted in an OS advantage (23.5 for zibotentan $10 \mathrm{mg}, 23.9$ months for zibotentan $15 \mathrm{mg}$ vs. 19.9 months for placebo: $\mathrm{p}=0.254$ and $\mathrm{p}=0.103$, respectively) (68). Three phase III Zibotentan Endothelin A Use (ENTHUSE) trials are ongoing in patients with CRPC (65).

Bone-targeted agents. Up to $75 \%$ of advanced prostate cancer patients develop bone metastases (70). Bone metastases lead to osteoclast-mediated bone destruction and clinical consequences include skeletal-related events (SREs) (71,72). Prostate cancer cells secrete osteogenic growth factors, activating osteoblasts to deposit new bone matrix; osteoblasts secrete a range of additional factors such as fibroblast growth factor, that attract prostate cancer cells, further enhancing their proliferation. RANKL-secreting osteoblasts can activate osteoclasts, leading to bone resorption. For that reason, several bone-targeted agents have been developed, most notably bisphosphonates, which are highly effective at stabilizing the bone and preventing skeletal complications (73-75).

In a multicenter, placebo-controlled phase III trial, 643 patients with metastatic CRPC were randomly assigned to receive intravenous zoledronic acid $(4 \mathrm{mg})$ or placebo, every 3 weeks for 15 months (core phase), with an option to continue for an additional 9-month extension phase (total study time: 24 months). The primary efficacy endpoint was the proportion of patients having at least one SRE, which was prospectively defined as a pathologic fracture, spinal cord compression, radiation therapy or surgery to bone, or change in the antineoplastic therapy to treat bone pain. Zoledronic acid reduced the incidence of SREs ( 38 vs. $49 \%$ : $p=0.028$ ), and the annual 


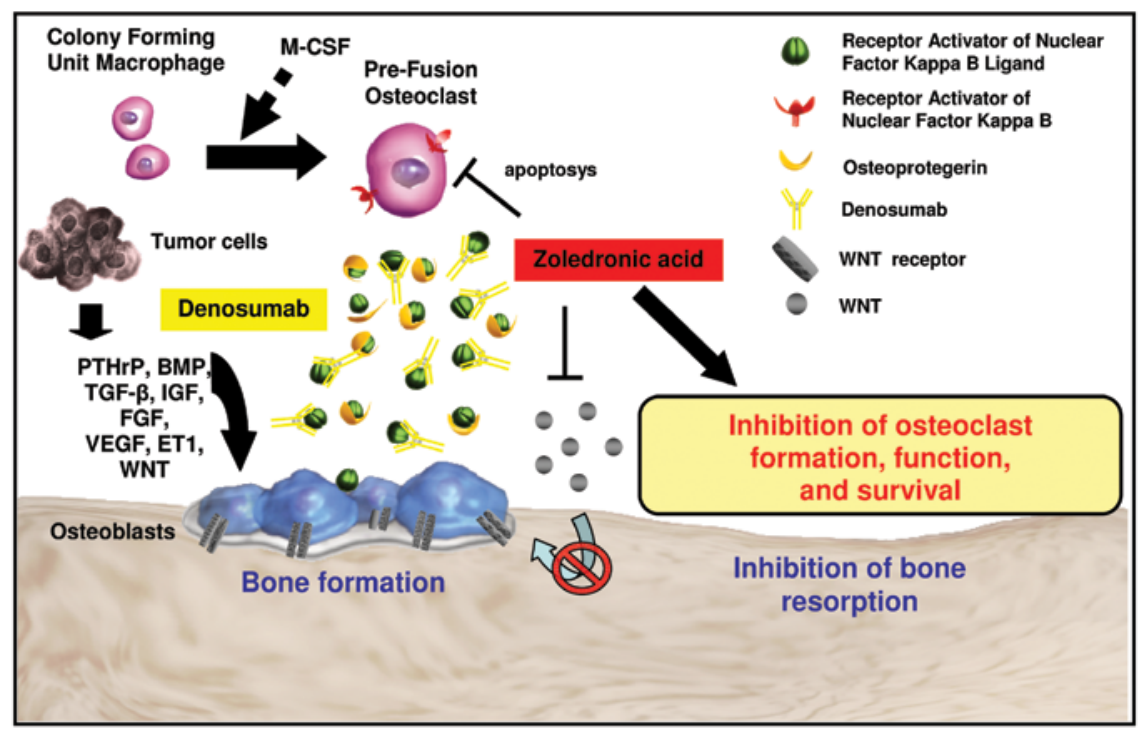

Figure 1. Possible mechanism of action of zoledronic acid and denosumab.

incidence of SREs was 0.77 for the zoledronic acid group versus 1.47 for the placebo group ( $\mathrm{p}=0.005)$. The median time to the first SRE was 488 days for the zoledronic acid group versus 321 days for the placebo group ( $\mathrm{p}=0.009)$. Compared with placebo, zoledronic acid reduced the ongoing risk of SREs by $36 \%(\mathrm{p}=0.002, \mathrm{RR}=0.64)$. Patients in the zoledronic acid group had a lower incidence of SREs than did patients in the placebo group, regardless of whether they had an SRE prior to entry in the study. Long-term treatment with zoledronic acid is safe and provides sustained clinical benefits for men with metastatic CRPC. In secondary endpoints, zoledronic acid improves OS of $\sim 2.7$ months $(\mathrm{p}=0.005)$ (76).

More recently, a nuclear factor- $\beta$ ligand (RANKL) inhibitor, denosumab, has been developed for the treatment of bone metastases. RANKL is involved in the regulation of bone metabolism and is overexpressed in osteoblasts associated with prostate cancer bone metastases in mice (77). Denosumab (120 mg subcutaneously q4 weeks) has been shown to significantly reduce and delay SREs similar to zoledronic acid in patients with bone metastases from breast cancer and other solid tumors $(78,79)$. A phase III, randomized, non-inferiority trial (NCT00321620) in patients with bone metastases from CRPC is currently comparing the benefit of denosumab and zoledronic acid based on time to the first on-study SRE (80). More frequent adverse events were hypocalcemia (especially asymptomatic) in the denosumab arm (12.8 vs. 5.8\% in the zoledronic arm), and acute phase reactions in the zoledronic $\operatorname{arm}(17.8$ vs. $8.4 \%$ in the denosumab arm). The possible mechanisms of action of zoledronic acid, one of the most frequently employed bisphosphonates, and of denosumab in patients with bone metastases, are outlined in Fig. 1.

The authors reported a relatively low incidence of cumulative rate of the osteonecrosis of the jaw (ONJ) in patients receiving zoledronic acid (1.3\%) and a similar incidence was observed in those receiving denosumab $(2.3 \% ; \mathrm{p}=0.09)(81)$. Several studies found that ONJ usually occurs after a longer duration of zoledronic acid treatment $(82,83)$ with a cumulative incidence of ONJ of $\sim 0.5 \%$ at 1 year, $1.2 \%$ at 2 years and $1.4 \%$ at 3 years (84). Therefore, considering that the average duration of this study is 12 month, it seems likely that the frequency of ONJ reported in the article is an underestimation of the actual ONJ frequency in both arms and that an additional and longer follow-up is necessary to draw final conclusions.

Another large, randomized, placebo-controlled trial was conducted to investigate the benefit of denosumab in patients receiving ADT, which can cause significant bone loss. Treatment with denosumab (60 mg q6 months) significantly increased bone mineral density of the lumbar spine at 24 months $(+5.6 \%$ vs. $-1 \%$ : $\mathrm{p}<0.001)$ and significantly reduced the incidence of new vertebral fractures ( 1.5 vs. $3.9 \%$ : $\mathrm{p}=0.006$ ) compared with placebo $(85,86)$.

\section{Conclusions}

The multidisciplinary management of advanced prostate cancer will no doubt continue to develop as chemotherapy and targeted agents are increasingly integrated into the treatment paradigm at all stages of disease to complement surgery, radiation, and hormonal therapies. Although the development of effective chemotherapy regimens for CRPC has led to significant improvements in OS, prognosis remains poor, and better treatment options are needed. At the present time, docetaxel represents the backbone of drug development strategies in CRPC, either as comparator in clinical trials or as the basis on which novel targeted agents are added. The natural history of CRPC is changing following the evidence that median OS has increased by 15 months after abiraterone and cabazitaxel treatment $(p<0.0001)$. Together, these drugs should be considered an effective second-line treatment following docetaxel and are approved since 2010 by US FDA.

The increasing knowledge of the molecular pathways that contribute to prostate cancer growth, androgen independence and bone metastases should result in a better control of CRPC. The identification of biomarkers for patient selection is urgently needed in order to better tailor treatment according to the molecular phenotype of the tumor. 


\section{Acknowledgements}

This work was supported by Associazione Italiana per la Ricerca sul cancro (AIRC), Investigator Grant and Special Program Molecular Clinical Oncology 5 per mille n. 9965, Milan.

\section{References}

1. Jemal A, Siegel R, Xu J and Ward E: Cancer statistics, 2010. CA Cancer J Clin 60: 277-300, 2010

2. Albertsen P: Androgen deprivation in prostate cancer - step by step. N Engl J Med 360: 572-574, 2009.

3. Cooperberg MR, Moul JW and Carroll PR: The changing face of prostate cancer. J Clin Oncol 23: 8146-8151, 2005.

4. Tannock IF, de Wit R, Berry WR, et al: Docetaxel plus prednisone or mitoxantrone plus prednisone for advanced prostate cancer. N Engl J Med 351: 1502-1512, 2004.

5. Harris WP, Mostaghel EA, Nelson PS and Montgomery B: Androgen deprivation therapy: progress in understanding mechanisms of resistance and optimizing androgen depletion. Nat Clin Pract Urol 6: 76-85, 2009.

6. Suzuki H, Kamiya N, Imamoto T, et al: Current topics and perspectives relating to hormone therapy for prostate cancer. Int J Clin Oncol 13: 401-410, 2008.

7. Donkena KV, Yuan H and Young CY: Recent advances in understanding hormonal therapy resistant prostate cancer. Curr Cancer Drug Targets 10: 402-410, 2010

8. Lam JS, Leppert JT, Vemulapalli SN, Shvarts O and Belldegrun AS Secondary hormonal therapy for advanced prostate cancer. J Urol 175: 27-34, 2006

9. Kelly WK and Scher HI: Prostate specific antigen decline after antiandrogen withdrawal: the flutamide withdrawal syndrome. J Urol 149: 607-609, 1993.

10. Lucas A and Petrylak DP: The case for early chemotherapy for the treatment of metastatic disease. J Urol 176: S72-S75, 2006.

11. Kantoff PW, Halabi S, Conaway M, et al: Hydrocortisone with or without mitoxantrone in men with hormone-refractory prostate cancer: results of the cancer and leukemia group B 9182 study. J Clin Oncol 17: 2506-2513, 1999.

12. Tannock IF, Osoba D, Stockler MR, et al: Chemotherapy with mitoxantrone plus prednisone or prednisone alone for symptomatic hormone-resistant prostate cancer: a Canadian randomized trial with palliative end points. J Clin Oncol 14: 1756-1764, 1996

13. Petrylak DP, Tangen CM, Hussain MH, et al: Docetaxel and estramustine compared with mitoxantrone and prednisone for advanced refractory prostate cancer. N Engl J Med 351: $1513-1520,2004$

14. Chang SS and Kibel AS: The role of systemic cytotoxic therapy for prostate cancer. BJU Int 103: 8-17, 2009.

15. Joly F and Tannock IF: Chemotherapy for patients with hormonerefractory prostate cancer. Ann Oncol 15: 1582-1584, 2004.

16. Dagher R, Li N, Abraham S, Rahman A, Sridhara R and Pazdur R: Approval summary: docetaxel in combination with prednisone for the treatment of androgen-independent hormone-refractory prostate cancer. Clin Cancer Res 10: 8147-8151, 2004.

17. Berry W, Dakhil S, Modiano M, Gregurich M and Asmar L: Phase III study of mitoxantrone plus low dose prednisone versus low dose prednisone alone in patients with asymptomatic hormone refractory prostate cancer. J Urol 168: 2439-2443, 2002.

18. Berthold DR, Pond GR, Soban F, de Wit R, Eisenberger M and Tannock IF: Docetaxel plus prednisone or mitoxantrone plus prednisone for advanced prostate cancer: updated survival in the TAX 327 study. J Clin Oncol 26: 242-245, 2008.

19. Armstrong AJ, Garrett-Mayer ES, Yang YC, de Wit R, Tannock IF and Eisenberger $\mathrm{M}$ : A contemporary prognostic nomogram for men with hormone-refractory metastatic prostate cancer: a TAX327 study analysis. Clin Cancer Res 13: 6396-6403, 2007.

20. Singh SM, Gauthier S and Labrie F: Androgen receptor antagonists (antiandrogens): structure-activity relationships. Curr Med Chem 7: 211-247, 2000.

21. Attard G, Reid AH, Olmos D and de Bono JS: Antitumor activity with CYP17 blockade indicates that castration-resistant prostate cancer frequently remains hormone driven. Cancer Res 69 4937-4940, 2009.

22. Attard G, Reid AH, A'Hern R, et al: Selective inhibition of CYP17 with abiraterone acetate is highly active in the treatment of castration-resistant prostate cancer. J Clin Oncol 27: 3742-3748, 2009.
23. National Institutes of Health: A phase 3, randomized, doubleblind, placebo-controlled study of abiraterone acetate (CB7630) plus prednisone in patients with metastatic castration-resistant prostate cancer who have failed docetaxel-based chemotherapy. http://clinicaltrials.gov/ct2/show/NCT00638690. Accessed October 2011.

24. De Bono JS, Logothetis CJ, Molina A, et al: Abiraterone and increased survival in metastatic prostate cancer. $\mathrm{N}$ Engl J Med 364: 1995-2005, 2011.

25. Scher HI, Beer TM, Higano CS, et al: ASCO Genitourinary Cancers Symposium 2011. J Clin Oncol 29 (Suppl 7): 4, 2011

26. Attard G, Greystoke A, Kaye S and De Bono JS: Update on tubulin-binding agents. J Pathol Biol 54: 72-84, 2006.

27. Pivot X, Koralewski P, Hidalgo JL, et al: A multicenter phase II study of XRP6258 administered as a 1-h i.v. infusion every 3 weeks in taxane-resistant metastatic breast cancer patients. Ann Oncol 19: 1547-1552, 2008

28. Mita AC, Denis LJ, Rowinsky EK, et al: Phase I and pharmacokinetic study of XRP6258 (RPR 116258A), a novel taxane, administered as a 1-hour infusion every 3 weeks in patients with advanced solid tumors. Clin Can Res 15: 723-730, 2009.

29. De Bono JS, Oudard S, Ozguroglu M, et al: Prednisone plus cabazitaxel or mitoxantrone for metastatic castration-resistant prostate cancer progressing after docetaxel treatment: a randomised open-label trial. Lancet 376: 1147-1154, 2010.

30. Bracarda S, Logothetis C, Sternberg CN and Oudard S: Current and emerging treatment modalities for metastatic castrationresistant prostate cancer. BJU Int 107 (Suppl 2): 13-20, 2011.

31. Latif T, Wood L, Connell C, Smith DC, Vaughn D, Lebwohl D and Peereboom D: Phase II study of oral bis (aceto) ammine dichloro (cyclohexamine) platinum (IV) (JM-216, BMS-182751) given daily x 5 in hormone refractory prostate cancer (HRPC). Invest New Drugs 23: 79-84, 2005.

32. Sternberg CN, Whelan P, Hetherington J, et al: Phase III trial of satraplatin, an oral platinum plus prednisone vs. prednisone alone in patients with hormone-refractory prostate cancer. Oncology 68: 2-9, 2005

33. Choy H, Park C and Yao M: Current status and future prospects for satraplatin, an oral platinum analogue. Clin Cancer Res 14: $1633-1638,2008$

34. Sternberg CN, Petrylak DP, Sartor O, et al: Multinational, double-blind, phase III study of prednisone and either satraplatin or placebo in patients with castrate-refractory prostate cancer progressing after prior chemotherapy: the SPARC trial. J Clin Oncol 27: 5431-5438, 2009.

35. Bianchini D, Zivi A, Sandhu S and de Bono JS: Horizon scanning for novel therapeutics for the treatment of prostate cancer. Ann Oncol 21 (Suppl 7): 43-55, 2010.

36. Small EJ, Schellhammer PF, Higano CS, et al: Placebocontrolled phase III trial of immunologic therapy with sipuleucel-T (APC8015) in patients with metastatic, asymptomatic hormone refractory prostate cancer. J Clin Oncol 24: 3089-3094, 2006.

37. Higano CS, Schellhammer PF, Small EJ, et al: Integrated data from 2 randomized, double-blind, placebo-controlled, phase 3 trials of active cellular immunotherapy with sipuleucel-T in advanced prostate cancer. Cancer 115: 3670-3679, 2009.

38. Kantoff PW, Higano CS, Shore ND, et al: Sipuleucel-T immunotherapy for castration-resistant prostate cancer. N Engl J Med 363: 411-422, 2010.

39. Hotte SJ and Saad F: Current management of castrate-resistant prostate cancer. Curr Oncol 17 (Suppl 2): 72-79, 2010.

40. Pal SK, Twardowski P and Sartor O: Critical appraisal of cabazitaxel in the management of advanced prostate cancer. Clin Interv Aging 5: 395-402, 2010.

41. Kantoff PW, Schuetz TJ, Blumenstein BA, et al: Overall survival analysis of a phase II randomized controlled trial of a Poxviral-based PSA-targeted immunotherapy in metastatic castration-resistant prostate cancer. J Clin Oncol 28: 1099-1105, 2010.

42. Cha $\mathrm{E}$ and Fong L: Therapeutic vaccines for prostate cancer Curr Opin Mol Ther 12: 77-85, 2010.

43. Tolcher AW: Preliminary phase I results of G3139 (bcl-2 antisense oligonucleotide) therapy in combination with docetaxel in hormone-refractory prostate cancer. Semin Oncol 28 (Suppl 15): 67-70, 2001

44. Sternberg CN: Docetaxel plus oblimersen sodium (Bcl-2 antisense oligonucleotide): an EORTC multicenter, randomized phase II study in patients with castration-resistant prostate cancer. Ann Oncol 20: 1264-1269, 2009. 
45. Vacca A, Ribatti D, Roncali L, Ranieri G, Serio G, Silvestris F and Dammacco F: Bone marrow angiogenesis and progression in multiple myeloma. Br J Haematol 87: 503-508, 1994.

46. Borre M, Offersen BV, Nerstrom B and Overgaard J: Microvessel density predicts survival in prostate cancer patients subjected to watchful waiting. Br J Cancer 78: 940-944, 1998.

47. Weidner N, Carroll PR, Flax J, Blumenfeld W and Folkman J: Tumor angiogenesis correlates with metastasis in invasive prostate carcinoma. Am J Pathol 143: 401-409, 1993.

48. Ferrer FA, Miller LJ, Lindquist R, Kowalczyk P, Laudone VP, Albertsen PC and Kreutzer DL: Expression of vascular endothelial growth factor receptors in human prostate cancer. Urology 54: 567-572, 1999.

49. Gnoni A, Marech I, Silvestris N, Vacca A and Lorusso V: Dasatinib: an anti-tumour agent via Src inhibition. Curr Drug Targets 12: 563-578, 2011.

50. Ranieri G, Patruno R, Ruggieri E, Montemurro S, Valerio $P$ and Ribatti D: Vascular endothelial growth factor (VEGF) as a target of bevacizumab in cancer: from the biology to the clinic. Curr Med Chem 13: 1845-1857, 2006.

51. Stavridi F, Karapanagiotou EM and Syrigos KN: Targeted therapeutic approaches for hormone-refractory prostate cancer. Cancer Treat Rev 36: 122-130, 2010.

52. Picus J, Halabi S, Kelly WK, Vogelzang NJ, Whang YE, Kaplan EB, Stadler WM and Small EJ; Cancer and Leukemia Group B: A phase 2 study of estramustine, docetaxel, and bevacizumab in men with castrate-resistant prostate cancer: results from Cancer and Leukemia Group B Study 90006. Cancer 117: 526-533, 2011

53. Di Lorenzo G, Figg WD, Fossa SD, et al: Combination of bevacizumab and docetaxel in docetaxel-pretreated hormone-refractory prostate cancer: a phase 2 study. Eur Urol 54: 1089-1094, 2008.

54. Kelly WK, Halabi S, Carducci MA, et al: A randomized, doubleblind, placebo-controlled phase III trial comparing docetaxel, prednisone, and placebo with docetaxel, prednisone, and bevacizumab in men with metastatic castration-resistant prostate cancer (mCRPC): survival results of CALGB 90401. J Clin Oncol 28 (Suppl): 18, 2010.

55. Verheul HM, Hammers H, van Erp K, et al: Vascular endothelial growth factor trap blocks tumor growth, metastasis formation, and vascular leakage in an orthotopic murine renal cell cancer model. Clin Cancer Res 13: 4201-4208, 2007.

56. National Institutes of Health: Aflibercept in combination with docetaxel in metastatic androgen independent prostate cancer (VENICE). http://clinicaltrials.gov/ct2/show/NCT00519285. Accessed October 2011.

57. Asim M, Siddiqui IA, Hafeez BB, Baniahmad A and Mukhtar H: Src kinase potentiates androgen receptor transactivation function and invasion of androgen-independent prostate cancer C4-2 cells Oncogene 27: 3596-3604, 2008.

58. Nam S, Kim D, Cheng JQ, et al: Action of the Src family kinase inhibitor, dasatinib (BMS-354825), on human prostate cancer cells. Cancer Res 65: 9185-9189, 2005.

59. Yu EY, Wilding G, Posadas E, et al: Phase II study of dasatinib in patients with metastatic castration-resistant prostate cancer. Clin Cancer Res 15: 7421-7428, 2009.

60. National Institutes of Health: Randomized study comparing docetaxel plus dasatinib to docetaxel plus placebo in castrationresistant prostate cancer. http://www.clinicaltrials.gov/ct2/show/ NCT00744497. Accessed October 2011.

61. Mooso B, Madhav A, Johnson S, et al: Androgen receptor regulation of vitamin $\mathrm{D}$ receptor in response of castration-resistant prostate cancer cells to $1 \alpha$-hydroxyvitamin D5 - a calcitriol analog. Genes Cancer 1: 927-940, 2010.

62. Beer TM, Eilers KM, Garzotto M, Egorin MJ, Lowe BA and Henner WD: Weekly high-dose calcitriol and docetaxel in metastatic androgen-independent prostate cancer. J Clin Oncol 21: 123-128, 2003

63. Beer TM, Ryan CW, Venner PM, et al: Double-blinded randomized study of high-dose calcitriol plus docetaxel compared with placebo plus docetaxel in androgen-independent prostate cancer: a report from the ASCENT Investigators. J Clin Oncol 25: 669-674, 2007

64. Scher HI, Jia X, Chi K, et al: Randomized, open-label phase III trial of docetaxel plus high-dose calcitriol versus docetaxel plus prednisone for patients with castration-resistant prostate cancer J Clin Oncol 29: 2191-2198, 2011.

65. Shepard DR and Dreicer R: Zibotentan for the treatment of castrate-resistant prostate cancer. Expert Opin Investig Drugs 19: 899-908, 2010
66. Carducci MA, Saad F, Abrahamsson PA, et al: A phase 3 randomized controlled trial of the efficacy and safety of atrasentan in men with metastatic hormone-refractory prostate cancer. Cancer 110: 1959-1966, 2007.

67. Nelson JB, Love W, Chin JL, et al: Phase 3, randomized, controlled trial of atrasentan in patients with nonmetastatic, hormonerefractory prostate cancer. Cancer 113: 2478-2487, 2008.

68. James ND, Caty A, Payne H, et al: Final safety and efficacy analysis of the specific endothelin A receptor antagonist zibotentan (ZD4054) in patients with metastatic castration-resistant prostate cancer and bone metastases who were pain-free or mildly symptomatic for pain: a double-blind, placebo-controlled, randomized phase II trial. BJU Int 106: 966-973, 2010.

69. James ND, Caty A, Borre M, et al: Safety and efficacy of the specific endothelin-A receptor antagonist ZD4054 in patients with hormone-resistant prostate cancer and bone metastases who were pain free or mildly symptomatic: a double-blind, placebocontrolled, randomised, phase 2 trial. Eur Urol 55: 1112-1123, 2009.

70. Coleman RE: Clinical features of metastatic bone disease and risk of skeletal morbidity. Clin Cancer Res 12: 6243-6249, 2006

71. Coleman RE: Metastatic bone disease: clinical features, pathophysiology and treatment strategies. Cancer Treat Rev 27: 165-176, 2001.

72. Scavelli C, Dammacco F, Vacca A, et al: Zoledronic acid affects over-angiogenic phenotype of endothelial cells in patients with multiple myeloma. Mol Cancer Ther 6: 3256-3262, 2007.

73. Tu SM, Mathew P, Wong FC, Jones D, Johnson MM and Logothetis CJ: Phase I study of concurrent weekly docetaxel and repeated samarium-153 lexidronam in patients with castration-resistant metastatic prostate cancer. J Clin Oncol 27: 3319-3324, 2009.

74. Tu SM, Millikan RE, Mengistu B, et al: Bone-targeted therapy for advanced androgen-independent carcinoma of the prostate: a randomised phase II trial. Lancet 357: 336-341, 2001.

75. Moschetta M, Gnoni A, Vacca A, et al: Bortezomib and zoledronic acid on angiogenic and vasculogenic activities of bone marrow macrophages in patients with multiple myeloma. Eur J Cancer 46: 420-429, 2010.

76. Saad F, Gleason DM, Murray R, et al: Zoledronic Acid Prostate Cancer Study Group. Long-term efficacy of zoledronic acid for the prevention of skeletal complications in patients with metastatic hormone-refractory prostate cancer. J Natl Cancer Inst 96: 879-882, 2004.

77. Fizazi K, Yang J, Peleg S, et al: Prostate cancer cells-osteoblast interaction shifts expression of growth/survival-related genes in prostate cancer and reduces expression of osteoprotegerin in osteoblasts. Clin Cancer Res 9: 2587-2597, 2003.

78. Henry D, von Moos R, Vadhan-Raj S, et al: A double-blind, randomized study of denosumab versus zoledronic acid for the treatment of bone metastases in patients with advanced cancer (excluding breast and prostate cancer) or multiple myeloma. Eur J Cancer 7 (Suppl): 12, 2009.

79. Stopeck A, Body J, Fujiwara Y, et al: Denosumab versus zoledronic acid for the treatment of breast cancer patients with bone metastases: results of a randomized phase 3 study. Eur J Cancer 7: (Suppl): 2, 2009

80. Fizazi K, Carducci M, Smith M, et al: Denosumab versus zoledronic acid for treatment of bone metastases in men with castration-resistant prostate cancer: a randomised, double-blind study. Lancet 377: 813-822, 2011.

81. Fusco V, Galassi C, Berruti A, et al: Osteonecrosis of the jaw after zoledronic acid and denosumab treatment. J Clin Oncol 29: e521-e522, 2011.

82. Ripamonti CI, Maniezzo M, Campa T, et al: Decreased occurrence of osteonecrosis of the jaw after implementation of dental preventive measures in solid tumour patients with bone metastases treated with bisphosphonates. The experience of the National Cancer Institute of Milan. Ann Oncol 20: 137-145, 2009.

83. Fusco V, Loidoris A, Colella G, Vescovi P and Campisi G: Osteonecrosis of the jaw (ONJ) risk in breast cancer patients after zoledronic acid treatment. Breast 19: 432-433, 2010.

84. Stopeck AT, Lipton A, Body JJ, et al: Denosumab compared with zoledronic acid for the treatment of bone metastases in patients with advanced breast cancer: a randomized, double-blind study. J Clin Oncol 28: 5132-5139, 2010.

85. Smith MR, Egerdie B, Hernandez Toriz N, et al: Denosumab in men receiving androgen-deprivation therapy for prostate cancer. N Engl J Med 361: 745-755, 2009.

86. Smith MR, Saad F, Egerdie B, et al: Effects of denosumab on bone mineral density in men receiving androgen deprivation therapy for prostate cancer. J Urol 182: 2670-2675, 2009. 